Respiration 2015;90:87

DOI: $10.1159 / 000431181$

\section{Specific Needs of Patients Attending Pulmonary Rehabilitation with an Interstitial Lung Disease Associated with Rheumatological Disease}

Emma E. Vincent Felix A. Woodhead

Institute for Lung Health, Glenfield Hospital, University Hospitals of Leicester, Leicester, UK

We read with great interest the paper by Holland et al. [1] addressing the specific needs of patients attending pulmonary rehabilitation (PR) with an interstitial lung disease (ILD) associated with rheumatological disease.

There is accumulating evidence to indicate that $\mathrm{PR}$ is safe and effective for patients with ILD [2]. In particular, there has been a recent focus on the importance of patients with idiopathic pulmonary fibrosis (IPF) attending classes. This may be due to idiopathic pulmonary fibrosis being the most common and progressive ILD, alongside the recent publication of quality standards [3].

Holland et al. [1] highlight the challenges of undertaking exercise regimens in patients with rheumatological ILD, not solely because of breathlessness, but also because of the additional difficulties related to joint pain, stiffness and inflammation. These extrapulmonary manifestations mean that, even with normal resting pulmonary function, subjects with rheumatoid arthritis have a lower cardiopulmonary exercise capacity than controls [4].
A factor, however, that was not directly addressed by Holland et al. [1] was the presentation of ILD in rheumatological patients. Because of locomotor difficulties and muscle weakness, in part associated with corticosteroid use, our experience is that patients often have a lower usual level of exercise than patients without joint disease. By the time they notice exertional breathlessness from ILD, disease extent is often greater than that of patients with idiopathic ILD at presentation, who are not limited by extrapulmonary disease. In addition, whilst rheumatologists are well aware of the importance of musculoskeletal physiotherapy, they may be less familiar with the role of PR.

Addressing the holistic needs of those patients with sarcoidosis and rheumatoid disease is a crucial part of exercise prescription to enhance the potential for the patients to progress during their course of PR. We hope to see future work that directly addresses the specific PR challenges of this group of patients.

\section{References}

1 Holland AE, Dowman LM, Hill CJ: Principles of rehabilitation and reactivation: interstitial lung disease, sarcoidosis and rheumatoid disease with respiratory involvement. Respiration 2015;89:89-99.

-2 Dowman L, Hill CJ, Holland AE: Pulmonary rehabilitation for interstitial lung disease. Cochrane Database Syst Rev 2014;10:CD006322.

3 NICE: IPF Quality Standards. 2015.

4 Cimen B, Deviren SD, Yorgancloğlu ZR: Pulmonary function tests, aerobic capacity, respiratory muscle strength and endurance of patients with rheumatoid arthritis. Clin Rheumatol 2001;20:168-173.
KARGER 125\%

(c) 2015 S. Karger AG, Basel

0025-7931/15/0901-0087\$39.50/0

E-Mail karger@karger.com

www.karger.com/res
Emma E. Vincent

Department of Respiratory Medicine

Glenfield Hospital, University Hospitals of Leicester

Leicester LE3 9QP (UK)

E-Mail emma.vincent@uhl-tr.nhs.uk 